analogy points to the probability of there being a decrease in the vertical force in the high latitudes of North America, or the equivalent to a red pole of increasing power repelling the needle for a large area around it.

The variations in the vertical force at and about these poles or foci of attraction and repulsion at different epochs are not yet sufficiently determined, but if the hypothesis of translation be given up, it is not unreasonable to suppose that the secular changes in the declination and inclination are chiefly dependent upon changes in the relative power of these poles.

No satisfactory explanation has yet been given of the remarkable changes in the earth's magnetic force as measured on its surface, and suggestions are only possible in the present instance.

The voyage of the Challenger has shown that local magnetic disturbance is found in the solitary islands of the sea, although surrounded by apparently normal conditions, similar to that on the great continents. It has also been suggested that the magnetic portions of these islands causing the disturbance may possibly "have been raised to the earth's surface from the magnetized portion of the earth forming the source of magnetism," and tending to prove Airy's conclusion " that the source of magnetism lies deep."

In view, therefore, of past geological changes and those now in progress, it may fairly be conceived, not only that large changes have likewise occurred in the distribution of the magnetic portions of the earth appearing here and there on the surface and producing local magnetic disturbance, but that there are others of a more progressive character below the earth's surface which are only made manifest by the secular change observed in the magnetic elements. This conception with regard to secular change is not intended to exclude the view that solar influences may have a small share in producing the observed phenomena.

In conclusion, it may be remarked that they who would fully see the substantial gains to terrestrial magnetism which have been obtained by the voyage of the Challenger must refer to the original of this abstract Report, with its plates and charts of the magnetic elements. Subsequent research may add to, qualify, or reverse the conclusions drawn from the observations, but the observations will probably retain a long-abiding value to magneticians.

$$
\text { E. W. CREAK. }
$$

\section{ON THE SUPPOSED ENORMOUS SHOWERS OF METEORITES IN THE DESERT OF ATACAMA.}

I $\mathrm{T}$ is now universally acknowledged both that meteorites come from outer space and that shooting-stars, whatever they are, have an extra-terrestrial origin. It is further asserted that a meteoritic fireball and a shootingstar are only varieties of one phenomenon. Indeed, after it is once granted that a meteoritic fireball is produced by the passage through the terrestrial atmosphere of a dense body entering it with planetary velocity from without, and that shooting-stars have an extra-terrestrial origin, it is a very fair assumption that a shooting-star is likewise a dense body rendered luminous during its atmospheric flight.

One great objection to this assertion is that, again and again, showers of hundreds of thousands of shootingstars have taken place, during which no heavy body has been observed to reach the earth's surface. The only known case of the arrival of a meteorite during a shootingstar shower has been that of Mazapil, on November 27 , I 885 , and that single coincidence may possibly be the result of accident. A sufficient explanation of this difficulty, however, is to be found in the small size of the individuals which produce the appearance of a shooting- star shower. That the individuals are really minute is proved by the fact that, while the total mass of a large swarm, like that producing the November meteors, is so small that there is no perceptible influence on the motion of the planets, the number of separate individuals is almost infinite. It is established that the Leonid swarm must be hundreds of millions of miles in length, and some hundreds of thousands of miles in thickness; and in the densest part of the Bielid swarm, passed through in 1885 , the average distance of the individuals from each other was about twenty miles.

Further, it is now acknowledged that comets are themselves meteoritic swarms, and $\mathrm{Mr}$. Lockyer has lately brought forward spectroscopic evidence that the fixed stars and the nebula are similar to comets in their constitution.

The question therefore immediately presents itself, Is the size of a meteoritic shower, on reaching the earth's surface, ever comparable with that of a meteoritic swarm, as manifested by a shower of shooting-stars?

During the present century nearly 300 meteoritic falls on the earth's surface have been observed, and on only a single date, namely August 25: 1865, has there been observed a fall on two distant parts of the earth on the same day. Un that date stones fell at Aumale in Algeria, and at Sherghotty in India ; but as the times of fall differed by about eight hours, and the stones arrived from different directions, it is more than probable that the coincidence of date was accidental. Hence we must infer that a swarm of meteorites, as far as actual observation of tangible objects goes, far from being hundreds of millions of miles long, with individuals a few miles apart, is a comparatively small group, separated from its neighbours, if it has any, by a distance comparable with the earth's diameter.

The extent of surface over which meteoric stones have been picked up after some of the best known and most widely spread falls is given in the following list :-
Limerick, 3 miles long.
Mocs, 3 miles by o. 6 mile.
Butsura, 3 miles by 2 miles.
Pultusk, 5 miles by I mile.
L'A igle, 6 miles by 2.5 miles.
Barbotan, 6 miles long.
West Liberty, 7 miles by 4 miles.
Stannern, 8 miles by 3 miles.
Knyahinya, 9 miles by 3 miles.
Weston, 10 miles long.
Hessle, ro miles by 3 miles.
New Concord, ro miles by 3 miles.
Castalia, Io miles by 3 miles.
Khairpur, 16 miles by 3 miles.

As far as I have yet been able to ascertain, the greatest observed separation has been sixteen miles. In the case of Macao, Cold Bokkeveldt, and Pillistfer, wider spreads have been chronicled, but later information has shown the inaccuracy of the earlier statements.

As regards the meteoric irons, there have only been nine observed falls since the year $175 \mathrm{I}$ : in seven of them only a single mass was found; in the remaining two there was in each case a couple of masses, not more than a mile apart. There is thus no recorded instance of an observed shower of meteoric iron. The most convincing proof of the actuality of such showers is furnished by the masses which have been found in the Valley of Toluca, in Mexico; their existence had been chronicled as early as the year 1784 , yet in 1856 it was still possible to collect as many as sixty-nine. When etched, they show the Widmanstätten figures in the most excellent way, and in their characters they are typical meteorites. Belonging, as they do, to a single type, they lead to the conviction that they are the result of a single shower. But the region over which the fall took place is not large; the 
length of it is said to have been only about fourteen miles.

It is very probable, though not conclusively proved, that large meteoritic showers of stones, like those of Pultusk and L'Aigle, reach the terrestrial atmosphere as swarms of isolated bodies; still, we must have regard to the fact that a mass is much fractured during its passage through the air by reason of the enormous pressure and the violent change of temperature. In the case of the Butsura fall, for example, it was conclusively established that stones picked up some miles apart must originally have formed part of a stone disrupted during the atmospheric flight.

It is a question of a certain amount of interest as to whether there is any evidence of the actual fall of a shower of meteorites over a large extent of the earth's surface.

Such evidence has long been supposed to be furnished by the plentiful occurrence of meteorites in the Desert of Atacama, a term applied to that part of Western South America which lies between the towns of Copiapo and Cobija, about 330 miles distant from each other, and which extends inland as far as the Indian hamlet of Antofagasta, about 180 miles from the coast.

The generally received impression as to the occurrence of meteorites in this desert is well illustrated by the following statement of M. Darlu, of Valparaiso, read to the French Academy of Sciences in 1845 :-

"For the last two years I have made observations of shooting-stars during the nights of November i 1 -November I 5 , without remarking a greater number than at other times. I was led to make these observations by the fact that in the Desert of Atacama, which begins at Copiapo, meteorites are met with at every step. I have heard, also, from one who is worthy of trust, that in the Argentine Republic, near Santiago del Estero, there is-so to say - a forest of enormous meteorites, the iron of which is employed by the inhabitants."

A study of the literature indicates that "the forest of enormous meteorites" near Santiago del Estero, understood by Darlu as significative of infinity of number, is really a free translation of a native statement "that there were several masses having the shape of huge trunks with deep roots," and that not more than four, or perhaps five, masses had really been seen in the Santiago locality at the time of Darlu's statement. There is a similar misunderstanding relative to the Atacama masses : it is clearly proved that, at a date long subsequent to 1845 , the Desert was virtually untrodden and unexplored. In Darlu's time it was onIy crossed along definite tracks by Indians travelling between San Pedro de Atacama and Copiapo, and between the inland Antofagasta and the coast. In fact, it is established that the only Atacama meteorites then in circulation were all got from a single small area, three or four leagues in length, in the neighbourhood of Imilac, one of the few watering-places on the track between San Pedro and Copiapo.

Since that time the discovery of rich silver-mines in the centre of the Desert, and the working of the nitrate deposits, have led to vast changes; the Desert has been more or less closely examined, and other meteoritic masses have been found. Still, the number of meteorites yet discovered, distinct either in mineralogical characters or locality, is shown to be, at most, thirteen.

One of them, Lutschaunig, is distinct from all the rest as being a chondritic stone; a second, Vaca Muerta, likewise differs from all the others in that it consists of nickel-iron and stony matter, both in large proportion; a third, Imilac, is a nickel-iron with cavities, like those of a sponge, filled with olivine; a fourth, Copiapo, is a nickel-iron with irregularly disposed angular inclosures of troilite and stony matter ; the remaining nine consist of nickel-iron, virtually free from silicates, some of them showing no Widmanstätten figures when etched, others showing excellent figures more or less differing in character.

Now, in every meteoritic shower yet observed, the individuals which have fallen simultaneously have been found to belong to a common type. Hence, it is reasonably certain that several distinct meteors are represented in the Desert, and that the above masses are the result of several falls; and this being accepted, the assertion of simultaneity of fall of two or more masses on the purely geographical ground that they have been found in the same Desert, can be allowed no great weight.

But have masses belonging to any one of the above types been found scattered over a part of the Desert so extensive as to indicate a meteoritic fall more widely spread than any of those actually observed? A critical examination of the cases in which such an enormous spread has been asserted proves that the evidence is quite unsatisfactory. The results may thus be summarized :-

(I) Lutschaunig.-This was a single stone.

(2) Vaca Muerta. - The masses were in great abundance distributed over a small area. But fragments undoubtedly belonging to this type have been brought from two other places far distant from the main locality. Very cogent evidence is brought forward to prove that the said fragments must have been carried to those places-the Jarquera Valley and Mejillones-from Vaca Muerta itself.

(3) Imilac.-An examination of all the known literature indicates that the whole of the fragments belonging to this type have been got from the immediate neighbourhood of Imilac. Caracoles, Potosi, and Campo de Pucará, from which specimens, belonging to this type, have been brought, are shown to be on regular lines of traffic starting from the Atacama coast. It is further shown that Imilac specimens were in great request, and were certainly carried to very distant places along such lines of traffic.

(4) Copiapo.-It is conclusively proved that the two localities, upwards of 400 miles apart, for meteoritic masses belonging to this type, result from a mere interchange of labels, and that all the masses probably came from a single place.

(5-I3) There is no satisfactory evidence furnished by similarity of type for any of the meteoric irons being part of a widespread shower.

It is thus clear that the meteorites of the Desert of Atacama afford absolutely no proof that enormous meteoritic showers have ever reached the earth's surface.

The general dryness of the air of the Desert, and the rarity of rain, have been sufficient to ensure the preservation of masses which have fallen in the course of many centuries unto a time when an exploration of a large extent of the Desert has taken place.

That the meteoritic masses are far from being so plentiful as has been imagined is conclusively proved by the experience of Mr. George Hicks, one of the earliest explorers of the $23 \mathrm{rd}$ and 24 th parallels; although much interested in their occurrence, he never found a mass himself, and he only obtained his first specimen after years of persevering inquiry from the Indians.

Detailed information relative to the Atacama meteorites, with a description and map of the Desert, will be found in the recently published number of the Mineralogical Magazine.

L. F.

\section{EARLY EGYPTIAN CIVILIZATION.}

$A$ LTHOUGH the paintings in the tombs of Memphis, of Beni Hasan, and of Thebes, have preserved to us the knowledge of much of the civilization of Egypt, yet hitherto we have handled but few examples of the im- 